\title{
Caridade, abre as asas sobre nós política de subvenções do governo Vargas entre 1931 e $1937^{*}$
}

\author{
Charity, spread your wings upon us \\ President Getúlio Vargas government's subvention policy, \\ from 1931 to 1937
}

\begin{abstract}
MaRcos gonçaLVES
Doutor em História pela Universidade Federal do Paraná Professor Adjunto da Universidade Estadual do Paraná/Campus Paranaguá Rua Comendador Corrêa Júnior, 117, CEP 83.203-560, Paranaguá/PR paideia_mg@yahoo.com.br
\end{abstract}

RESUMO O artigo discute o funcionamento da Caixa de Subvenções criada pelo governo Vargas através do Decreto 20.351 de agosto de 1931. Analisa os fatores e condições que propiciaram a esse dispositivo legal ter contribuído para uma aliança mais franca e consolidada entre o Estado e a Igreja católica pelo exercício da caridade, modalidade vista aqui como núcleo de interdependência entre as duas esferas. Questiona, em conclusão, sobre a fluidez entre público e privado, e sobre os limites e fragilidades do processo de laicização as sociedade brasileira.

Palavras-chave caridade, política, Igreja católica, Getúlio Vargas, subvenções

ABSTRACT The article discusses the functioning of the Subvention Organization created by the President GetúlioVargas government through the August 1931's Decree n.20.351. It analyses factors and conditions that made

Artigo recebido em: 12/04/2010. Aprovado em: 23/09/2010. 
such a legal mechanism to contribute to a more open and consolidated alliance between the State and the Catholic church by means of charityoriented actions, modality seen as the core of interdependence between the two organisations. In conclusion, it questions the fluidity among public and private matters as well as the limits and weaknesses of the Brazilian society laicization process.

Keywords charity, politics, Catholic church, Getúlio Vargas, government, subvention

É reconhecido plenamente que ao longo das décadas de 1920 e 1930 houve uma expansão de medidas políticas voltadas à assistência aos pobres na forma de caridade e/ou filantropia. Direta ou indiretamente, essas políticas agiram em favor da união de interesses entre o Estado brasileiro e a Igreja católica, o que significou para esta última, um acréscimo em número de instituições e no prestígio que angariou para o desenvolvimento da assistência nos moldes cristãos. ${ }^{1}$

Nessa época, o relativo alcance das tensões que marcaram desde 1889 o convívio entre a República e a Igreja foi superado pela remoção de um paradoxo vivenciado pelas elites republicanas. Ao fundarem um Estado laico no qual iriam predominar episodicamente correntes anticlericais, essas elites demonstraram pouca disposição em assumir de forma pragmática a separação Estado-Igreja de 1890, substituindo-a, para empregarmos um termo weberiano, por uma afinidade eletiva que implicou na atração recíproca entre sucessivos governos políticos e católicos para que objetivos aparentados pudessem realizar-se. Limitaram-se tais elites, com efeito, a produzir um exercício retórico que parecia mais expor precauções diante da maioria católica, e menos uma ação que aprofundasse medidas de laicização afeitas às sociedades políticas contemporâneas.

Entre o período demarcado pelo governo provisório e o governo constitucional de Vargas (1930-1937), foi que a Igreja e suas organizações mais puderam usufruir, legal e financeiramente, de benefícios direcionados ao

1 Neste sentido, ver, entre outros, os seguintes estudos que, explícita ou implicitamente destacam a influência da Igreja: ALAYÓN, Norberto. Assistência e assistencialismo: controle dos pobres ou erradicação da pobreza? 2a.ed. São Paulo: Cortez, 1995; AZZI, Riolando e GRIJP, Klaus van der. História da Igreja no Brasil: Ensaio de interpretação a partir do povo. Petrópolis: Vozes, 2008, t.II/3-2, Terceira Época (1930-1964); IAMAMOTO, Marilda e CARVALHO, Raul de. Relações sociais e serviço social no Brasil: esboço de uma interpretação histórico-metodológica. $22^{a}$.ed. São Paulo: Cortez, 2008; DUARTE, Adriano Luiz. Cidadania e exclusão: Brasil 1937-1945. Florianópolis: UFSC, 1999; MESTRINER, Maria Luiza. O Estado entre a filantropia e a assistência social. São Paulo: Cortez, 2001; SERBIN, Kenneth P. Brazil: State subsidization and the Church since 1930. In: PATTNAYAK, Satya. (org.) Organized religion in the political transformation of Latin America. New York: University Press of America, 1995, p.153-175. 
desenvolvimento de seus projetos pastorais e administrativos no campo específico da caridade.

Tomando como base essa especificidade, o propósito do artigo é refletir sobre a criação e o papel assumido pela Caixa de Subvenções dentro da periodização referida. A hipótese é de que esse organismo surgido pelo Decreto 20.351 de 31/08/1931, e desvinculado dos campos legais da regulação do trabalho e da previdência social, robusteceu a aliança entre o Estado e o catolicismo, conferindo à Igreja um estatuto legitimador que a consolidou como a mais fiel parceira da república laica.

A Caixa de Subvenções, destinada a auxiliar estabelecimentos de caridade, órgãos de natureza técnico-educacional e prover recursos para a nacionalização de ensino, pela sua amplitude e generalidade, talvez não tenha encontrado paralelos na história republicana até aquele momento. Da mesma forma, a majoração sobre o discurso da caridade como política de Estado, era algo que não se realizaria sem a presença, a influência e o ativismo de ordens religiosas e instituições geridas por católicos, vistas como centrais para a execução do programa.

\section{Entre caridade e política: a república das subvenções}

Na década de 1930, a caridade se apresenta como termo-chave que nos aproxima da compreensão sobre o funcionamento das políticas de subvenção praticadas pelo governo. Desenvolvidas pela práxis racional-legal elas permitiram o trânsito nas relações entre Estado e sociedade civil, e, particularmente, entre Estado e catolicismo em, pelo menos, dupla valência: assistir ao exército de desvalidos, órfãos, "artífices do ócio"² que estavam à margem do discurso de modernização proposto pelo Estado no pós 1930; e garantir o fluxo ininterrupto de recursos para centenas de organizações particulares que se ofereciam como portadoras de um projeto público de perfil salvacionista.

Foi somente no início do decênio seguinte que houve uma mudança de perspectiva em termos de métodos de abordar a miséria social, verificandose esse deslocamento, também em núcleos assistenciais administrados por católicos. Como assinalou Riolando Azzi, embora o discurso eclesiástico continuasse pregando o amparo à população desvalida, sob o pilar do princípio caritativo, existiu ali a insistência para que tal prática fosse conduzida de maneira mais racionalizada. ${ }^{3} \mathrm{O}$ empenho em criar medidas preventivas contra a miséria e não só levar adiante ações pálio-caritativas que reforça-

2 Em alusão ao livro de: ZANIRATO, Silvia Helena. Artífices do ócio. Mendigos e vadios em São Paulo (1933-1942). Londrina: EDUEL, 1998.

3 AZZI, Riolando. História da lgreja, p.21. 
vam a resignação, a paciência e aceitação do destino forneceu suportes metodológicos para que surgisse no Brasil a disciplina de Serviço Social.

A prática da caridade por instituições religiosas, porém, não se configura em novidade na história social brasileira e toma parte de uma longa tradição estabelecida desde os tempos da sociedade colonial. Essa tradição, iniciada pela criação das casas de misericórdia ainda no século XVI guarda fortes vínculos com o perfil assumido pela administração ibérica nas Américas. A Igreja ocupou o vazio criado deliberadamente por um Estado escravocrata, excludente, descompromissado e pouco interessado quanto ao cumprimento de um mínimo necessário às populações enjeitadas. Seja porque antes respondia às injunções da política regalista; seja porque a prática da caridade situa-se no cerne do pensamento cristão e se agrega ao catolicismo como fonte de poder social, o fato evidente é que no terreno de serviços sanitários, hospitalares e de socorro aos pobres, a Igreja teria recebido, em contrapartida, regular atendimento em suas petições de auxílios econômicos.

Na conjuntura aqui analisada, entretanto, o discurso se refazia sob a modelagem, mesmo que precária e parcialmente assimilada da Doutrina Social da Igreja, e os católicos produziam a crença de que nada poderia ser realizado ou nenhuma reforma social concretizar-se-ia sem a delimitação clara de políticas que incorporassem o caráter cristão ao ambiente laico. A normatividade das regras sociais deveria submeter-se, pois, a uma ética transcendente buscada para além do mundo físico mas que pudesse contar com a ajuda material das instituições políticas. Na imprensa confessional católica, por exemplo, predominava essa ambição integrista de que o pensamento social, sobretudo, quando elaborado para o atendimento aos pobres, deveria se converter em pensamento teologal. Vejamos o que escreveu em janeiro de 1937 no influente periódico mariano Ave Maria, o padre Asterio Paschoal, membro da congregação claretiana. Ele parecia ratificar o argumento "salvação pública mais caridade cristã" exatamente em contexto no qual as associações católicas mais se empenhavam numa equação correlata: "caridade mais recursos públicos". Dizia Asterio:

Ninguém se canse, entretanto, em procurar esse pensamento, essa base da sociedade senão for hauri-lo na mesma fonte, na mesma origem da sociedade. E de mãos à boca aparece-nos Deus ligado ao homem pela religião, unido à sociedade pelo culto religioso. Dessa forma o pensamento social se converte em pensamento teologal. Assim se torna a sociedade verdadeiro centro da vida, verdadeiro meio de felicidade. ${ }^{4}$

4 PASCHOAL, Asterio. Movimento social com caráter cristão. Revista Ave Maria, p.67-68, n.5, 30 de janeiro de 1937. 
Os pobres atraíam a diligência do catolicismo, porque na opinião de Paschoal, o Estado reconhecia o influxo e a adaptação progressiva desse espírito na moralização dos costumes públicos, na eliminação de antagonismos e apetites desmedidos, na suavização das consciências e na construção de "uma comunidade integrada por pobres e favorecidos da fortuna, onde todos se amam e todos se auxiliam". ${ }^{5}$ Em outras palavras, forjava-se uma síntese de corporativismo católico e política autoritária, que não abdicava, entretanto, dos postulados capitalistas. Como disse Hobsbawm, referindo-se às cidades burguesas e modernas de final do século $\mathrm{XIX}$, mas que pode valer para a realidade aqui investigada, talvez os pobres representassem algo incômodo e sua presença nas áreas urbanizadas era mal recebida, mas não deixavam de ser um "mal necessário". 6

A prática de subvenções no primeiro período varguista teria funcionado como uma alavanca que empurrou mais ainda as entidades católicas privadas para dentro do Estado, tendo em vista o expressivo contingente desse "mal necessário", matéria-prima da caridade. Por outro lado, se considerarmos que a criação da Caixa de Subvenções inscreveu-se como uma medida que assinalou um modelo político em estruturação, não devemos esquecer que tal modelo teve correspondência, em termos de impacto, com um amplo espectro de políticas sociais erigidas também sob um novo significado ideológico. Essas políticas sociais obtinham dimensões sem precedentes no debate orientado pelo contexto de inícios da década de 1930, e o objetivo proposto pelos programas de subvenções, agregou-se, com efeito, a construções políticas análogas.

Foi com pertinência que Ângela Gomes refletiu sobre a ligação existente entre a emergência de governos autoritários no Brasil e os avanços na legislação social, com a nítida intervenção regulatória crescente e não mais interrompida, pelo menos, durante muitas décadas:

O exame da evolução da política social no Brasil demonstra, de forma nítida, um fato de suma significação: é justamente nos períodos de existência de governos autoritários que os mais substanciais progressos na legislação social podem ser observados, quer consideremos o conjunto de benefícios e serviços integrados ao corpo desta legislação, quer consideremos o número de beneficiários por ela atingido. Neste sentido, a década de 30 é um marco no curso dessa evolução. ${ }^{7}$

Dentre os avanços dessas políticas, lembremos os seminais projetos que negociaram a organização da esfera do trabalho, com derivações na legislação previdenciária e na medicina do trabalho. Ao lado destes,

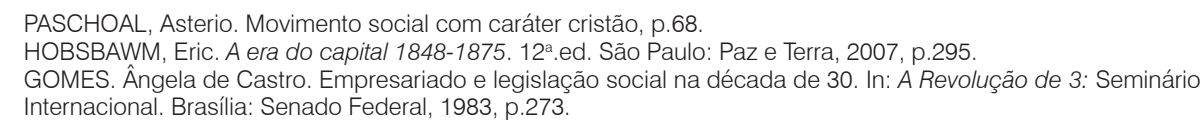


elaborou-se uma nova ótica situada sobre a necessidade de refinar a burocracia estatal, com a decorrente qualificação técnica e política concretizada nas instâncias administrativas que germinaram como gestoras do negócio público. Igualmente, seria falho não mencionar a alteração substancial pela qual passou a política econômica, orientando-se ideologicamente no sentido do "nacionalismo", e da expansão da "industrialização", com a forte presença do Estado nos setores de infra-estrutura. ${ }^{8}$

A esse conjunto de soluções que esperava contrapor-se a um passado de mazelas e corrupções, incorporou-se a necessidade de construir um mecanismo legal que abrangesse o campo da assistência não somente vinculada à formatação jurídica do trabalho e à previdência social do trabaIhador. Esse mecanismo foi denominado de Caixa de Subvenções, criado pelo Decreto 20.351 de 31 de agosto de 1931. O objetivo do item seguinte é decompô-lo em suas finalidades, e valorizar criticamente os aspectos que estabeleceram sua pretensa impessoalidade.

\section{O decreto 20.351 - gênese da caridade na década de 1930}

O surgimento da Caixa de Subvenções, como foi frisado, alcançou amplas dimensões, e, possivelmente, dada sua generalidade, não tenha encontrado paralelos até então, consoantes aos múltiplos fins que desejava atingir.

O levantamento realizado por esta pesquisa contemplou todos os atos (decretos) agrupados nas coletâneas da legislação federal e nas coleções do Diário Oficial da União situando os dispositivos pelos quais o Estado concedeu subvenções entre dezembro de 1931, data do primeiro auxílio, a dezembro de 1937. A data de corte final significa que a partir de 1938, com a criação do CNSS - Conselho Nacional de Serviço Social (DecretoLei 525 de 1 de julho), a política de subvenções passou a ser orientada por um novo tipo de estratégia. Na opinião de Mestriner, o CNSS consolidou a estratégia de aliança do Estado com a sociedade civil, via filantropia, mas também operou numa vertente fundamentada em métodos mais científicos e racionalizados. ${ }^{9}$ Não nos deteremos aqui sobre a política do CNSS, mesmo porque, ele ultrapassa o nosso período. Além disso, Mestriner abordou de forma aprofundada e com rara eficácia metodológica o papel desse órgão. Faremos remissão a esse importante trabalho para questioná-lo, sobretudo, a respeito do tempo de vida da Caixa de Subvenções.

8 Ver: LAMOUNIER, Bolívar. Do modelo institucional dos anos 30 ao fim da era Vargas. In: D’ARAÚJO, Maria Celina. (org.) As instituições brasileiras da era Vargas. Rio de Janeiro: Eduerj/FGV, 1999, p.38. Segundo Boris Fausto, tal expansão deveu-se menos a uma política deliberada do governo Vargas e mais à conjuntura internacional. Com a desvalorização da moeda brasileira houve a possibilidade de iniciar-se um processo de substituição de importações. Com efeito, no período de 1933 a 1939, a indústria teria crescido a uma taxa anual de 11,2\%, sobretudo, no setor da metalurgia de pequeno porte e bens de consumo, como papel e papelão, têxteis, vestuários e calçados. Ver: FAUSTO, Boris. Getúlio Vargas: o poder e o sorriso. São Paulo: Companhia das Letras, 2006, p.45.

9 MESTRINER, Maria Luiza. O Estado entre a filantropia e a assistência social, p.51. 
Quanto à aplicação das disposições do Decreto 20351, elas dependeram, ao longo de sua existência, de várias modificações e artifícios burocráticos: 1) mudança do Ministério gestor do programa; 2) transformação, por lei, dos fundos pecuniários das subvenções em verba de despesa permanente da União; 3) complementação sistemática de verbas, menos para dinamizar o programa e mais para manter uma sobrevida da Caixa até a criação de mecanismos mais eficientes; 4) drenagem contábil de verbas consignadas originalmente em outras despesas para o atendimento da conta das subvenções, com aprovação do Tribunal de Contas da União. Vejamos, pois, as justificativas para o surgimento da Caixa de Subvenções a partir de uma leitura pormenorizada do próprio Decreto de criação.

Paralelamente aos serviços públicos de assistência, tinha o Estado o dever de subvencionar os estabelecimentos de iniciativa particular com as mesmas finalidades. Criara assim, a Caixa de Subvenções para amparar com eficiência e assistir, dentro de um espírito de "altruísmo" as associações contempladas. A perspectiva era estabelecer normas preventivas de burla e dos meros favores pessoais ou políticos, "no manifesto interesse dos verdadeiros desprotegidos e da economia do país". ${ }^{10}$

Ressaltava já nesse preâmbulo de considerandos o empenho em uma abordagem que esperava primar pela eficiência e racionalização. Uma economia modernizadora e ascética, que visava dar cabo, pelo menos formalmente, do privatismo que assolava o espaço compreendido pelo político.

Esse imperativo denunciava o emprego equivocado da máquina governamental quanto ao campo da assistência, induzindo que dali em diante os procedimentos seriam pautados por decisões técnicas e racionalidade administrativa. Com a ênfase postada no rigor de organização e distribuição de recursos, o argumento abaixo indicava explicitamente a falência dos métodos arcaicos de gestão empregados anteriormente:

Considerando que os auxílios prestados pelo Governo Nacional devem ser distribuídos com eficiência, tendo-se em vista garantir e desenvolver, ao longo do território brasileiro, a organização e real utilidade dos estabelecimentos;

Considerando que as dotações consignadas, na maioria sem conhecimento prévio do mérito das instituições e sem a relativa uniformidade, representando pesado ônus às finanças públicas, não têm tido distribuição proporcional às respectivas necessidades;

Considerando que essa situação impõe, além das indispensáveis medidas de prevenção e garantia, a organização de uma caixa especial, onde fiquem centralizados auxílios já existentes e os que possam ser concedidos pelo governo. ${ }^{11}$

10 Cf. Preâmbulo do Decreto 20.351 de 31 de agosto de 1931. In: BRASIL. Colleção das Leis da República dos Estados Unidos do Brasil de 1931. Rio de Janeiro: Imprensa Nacional, 1931, v.lll - Atos do Governo Provisório (maio a agosto), p.708.

11 Cf. Preâmbulo do Decreto 20.351 de 31 de agosto de 1931, p.708. 
Qual era a natureza das instituições atendidas e por quais meios deveriam estar constituídos os recursos? A Caixa de Subvenções tinha alcance sobre várias modalidades de associações: hospitais, maternidades, creches, leprosários, institutos de proteção à infância e à velhice desvalida, asilos de mendicidade, cegos e surdos-mudos, orfanatos, ambulatórios para tuberculosos, dispensários e congêneres, bem como os estabelecimentos de ensino técnico não custeado pela União, pelos Estados ou municípios. Ainda por conta dos recursos da Caixa, o governo atendeu aos três Estados do sul do país que mantinham serviços de nacionalização de ensino, obrigando, "nas escolas primárias, o ensino da língua portuguesa, geografia do Brasil e história Pátria". ${ }^{12}$ Recorde-se que outros dispositivos vieram a completar lacunas deixadas pelo Decreto 20351. Este foi o caso, por exemplo, do Decreto 20597 de 3 de novembro de 1931, incluindo como beneficiários da lei original as instituições ou corporações científicas de "reconhecida utilidade pública, a juízo do governo" que "prestavam serviços à coletividade (...), objetivos de filantropia ou de alevantamento dos foros científicos da nacionalidade". ${ }^{13}$

Antes de ser implantada na qualidade de verba permanente da União, a Caixa definiu quatro variantes de captação de recursos para sua constituição: 1) produto da contribuição de caridade cobrada nas alfândegas da República, sobre vinhos e mais bebidas alcoólicas e fermentadas; 2) produto da taxa especial sobre embarcações; 3 ) créditos orçamentários e especiais a esse fim destinados; 4) produto de donativos e outros quaisquer que podiam ser concedidos em favor da Caixa de Subvenções.

Para se habilitarem ao recebimento de recursos, os estabelecimentos deveriam atender certas exigências. Na apresentação de memorial descritivo sobre as condições da instituição postulante ao auxílio eram requeridos comprovação de funcionamento por mais de dois anos; prova de que não recebia qualquer subvenção da União nem dispunha de recursos próprios suficientes para o custeio de suas despesas; indicação do número de beneficiários; prestação de serviços gratuitos; juntada de balancetes relativos ao último semestre de funcionamento.

Quanto à forma de fiscalização e inspeção dos estabelecimentos, o decreto mandava que o Ministério da Justiça e Negócios Interiores designasse funcionários de sua imediata confiança, em número não superior a cinco. Competiam a esses funcionários, três funções básicas: inspecionar todas as dependências do estabelecimento, de modo a poder fazer juízo completo sobre as suas condições de higiene e instalação, bem como sobre a eficiência de todos os serviços, notadamente os que fossem prestados

12 Cf. Artigo 22 do Decreto 20.351 de 31 de agosto de 1931, p.712.

13 Decreto 20.597 de 3 de novembro de 1931. In: BRASIL. Colleção das Leis da República dos Estados Unidos do Brasil de 1931, v.lll - Atos do Governo Provisório (setembro a novembro), p.424. 
gratuitamente; verificar se o auxílio concedido fora dado em proporções aos serviços prestados e se eram observados pelos dirigentes da instituição os dispositivos do regulamento, estatuto ou compromisso, podendo exigir todos os elementos e informações necessários à perfeita elucidação desse ponto; examinar os livros de receita e despesa, matrículas, registros e outros a respeito da vida interna do estabelecimento, podendo exigir contratos, compromissos ou termos de responsabilidade, dos quais decorriam ônus à instituição.

Administrada em seus primeiros meses de existência pelo Ministério da Justiça e Negócios Interiores, a Caixa de Subvenções, a partir de março de 1932 passou à competência do Ministério de Educação e Saúde Pública. ${ }^{14}$ Julgava o Governo que por intermédio de um órgão com o perfil do MESP com mais eficácia seria exercida a fiscalização das instituições, além do que, as atividades da Caixa mais bem se adequariam nas atribuições específicas dessa área. Este fato, além de marcar uma mudança de perspectiva na forma de administração, pois delegava a um órgão que teria decisiva influência na política varguista até o fim do Estado Novo, também contraria as afirmações de Mestriner quanto ao argumento de que a Caixa permaneceu sob gestão do Ministério da Justiça durante toda a sua vigência. ${ }^{15}$

Esse Ministério foi responsável pela Caixa durante um período de seis meses, após o que, todas as atribuições relativas ao programa foram transferidas até 1937 para o Ministério de Educação e Saúde Pública. Outro dado questionável no estudo de Mestriner é quanto ao tempo de existência da Caixa de Subvenções. Afirma a autora que antes da criação do CNSS em 1938, "o presidente Vargas teve junto ao seu gabinete um conselho consultivo - em substituição à Caixa de Subvenções (extinta em 1935), composto por cinco especialistas na área social e nove elementos do governo". ${ }^{16}$

Ora, até dezembro de 1937, independentemente ou não da existência de um conselho consultivo, todos os decretos que concederam subvenções invocaram explicitamente em súmula o Decreto 20.351 como amparo legal para a concessão de auxílios. Ademais, não se pode entender qual a relação entre o funcionamento de um conselho consultivo e a continuidade ou não de uma Caixa dotada de recursos próprios para distribuição entre instituições credenciadas. Ambos poderiam conviver dentro da mesma estrutura burocrática, atuando o conselho técnico como o filtro dos pedidos de auxílios encaminhados. Mesmo que sua configuração passasse por modificações que visaram adaptá-la a uma dinâmica mais racional, a Caixa de Subvenções predominou sobre outras iniciativas na sua função

14 Ver: Decreto 21.220 de 30 de março de 1932. In: BRASIL. Colleção das Leis da República dos Estados Unidos do Brasil de 1932, v.l - Atos do Governo Provisório (setembro a novembro), p.424.

15 MESTRINER, Maria Luiza. O Estado entre a filantropia e a assistência social, p.67.

16 MESTRINER, Maria Luiza. O Estado entre a filantropia e a assistência social, p.56. 
de principal mecanismo de respaldo à assistência social e distribuição de recursos até que fosse substituída pelo CNSS, criado em meados de 1938. Assim, o último decreto localizado pela nossa pesquisa sobre a concessão de auxílios e que ainda faz referência ao Decreto 20.351, foi o de n. 2.186 de 20 de dezembro de $1937 . .^{17}$

Por outro lado, tem razão Mestriner quando considera a Caixa de Subvenções quanto o futuro Conselho Nacional de Serviço Social ou muitas das políticas subsidiárias em áreas que afetam a "justiça social" como instrumentos de fronteiras imprecisas da relação entre o estado e as organizações filantrópicas de natureza privada. O Estado fez com que a assistência social transitasse no campo da solidariedade, filantropia (que é o equivalente laico à caridade cristã) e benemerência, princípios que nem sempre representam direitos sociais, mas apenas benevolência paliativa. ${ }^{18}$

A Caixa de Subvenções incentivaria e impulsionaria formas embrionárias de um nonprofit setor, para empregarmos uma terminologia bastante em moda nos últimos tempos. Ou seja, o surgimento de uma terceira via desvinculada das amarras estatais, mas instituída de funções públicas, e recebendo, para tanto, lautos subsídios.

Isto também leva a encetar uma reflexão relacionada ao público e ao privado especificamente quanto aos propósitos da Caixa de Subvenções. Ancorados na densa análise de Ângela Gomes sobre o tema, assinalamos que tal programa de subvenções é típico de uma política de fronteiras, que é, na realidade, facilmente permutável. A política das subvenções, ao lado de outras, era uma equação colocada para solucionar e superar possivelmente um dilema: de uma parte, consolidar o paradigma de política moderna, criando um mundo de cidadãos "racionais", sob convivência de procedimentos públicos impessoais. De outra parte, e tal como refere a autora, compreender uma realidade que se confrontava com esse "público", reconhecendo a existência de padrões de autoridade tradicional (personalizada e emocional). ${ }^{19}$

As subvenções fundavam a necessidade de um espírito de previsão, antecipação, e delineamento burocrático para se atingir os canais competentes em busca do recurso, mas também permitiam a contemporização, a conciliação e o apagamento da ambiguidade público/privado, graças à existência de uma última instância reguladora e decisória consubstanciada na figura que encarnava a categoria individual/coletivo e que destruía o dilema: Vargas. Ele devia personificar esse estado de coisas público para

17 Cf. Decreto 2.186 de 20 dezembro de 1937. In: Diário Oficial da União, n.295 de 27 de dezembro de 1937, p.25.584-25.585.

18 MESTRINER, Maria Luiza. O Estado entre a filantropia e a assistência social, p.21.

19 GOMES, Ângela de Castro. A política brasileira em busca da modernidade: na fronteira entre o público e o privado. In: NOVAIS, Fernando. (dir.) História da vida privada no Brasil. Contrastes da intimidade contemporânea. São Paulo: Companhia das Letras, 2007, v.4, p.499. 
que se realizasse o ocultamento da distância que separava o privado das decisões impessoais.

Prática usual de governos com feitio autoritário e paternalista, a política de subvenções, como se fosse uma casca de impessoalidade ajudava a disfarçar o discurso sobre a modernização política, e oferecia chances para o que Alain Rouquié, designou, referindo-se aos contextos latino-americanos, de "mobilização conforme". Essa "mobilização conforme", segundo o autor, situa-se nas camadas subordinadas e efetua-se por meio de instituições e procedimentos diversos que se apresentam com um denominador comum. Nele, o Estado se substitui por múltiplos patrões independentes e instaura um clientelismo de massa, que dá uma dimensão impessoal aos mecanismos de troca sóciopolítica, sem por isso abrir mão dos critérios de proteção e de dependência. ${ }^{20}$

\section{A geografia da caridade}

O termo "geografia da caridade" foi adotado aqui para discernir como a distribuição de subvenções abarcava as regiões atendidas e qual a tipologia de recursos canalizados mais frequente e significativa. A geografia também ajuda a tornar explícita a capacidade de desdobramento de subvenções, que, evidentemente, não se limitavam ao exercício da caridade. Os Quadros demonstrativos seguintes dizem respeito ao montante de recursos alocados no período 1931-37, à região de destino das subvenções e ao percentual respectivo endereçado às regiões para cada tipo de subvenção.

Para identificarmos as tipologias de subvenções, foi estabelecida a seguinte convenção: S1, para demonstrar o montante de subvenções destinadas a atender hospitais, asilos, orfanatos, Misericórdias, leprosários, missões religiosas, institutos de caridade em geral; $\mathbf{S 2}$, para os recursos canalizados aos estabelecimentos profissionais de fomento técnico, cultural, comercial e instituições de ensino; $\mathbf{S 3}$, para as subvenções concedidas à política de nacionalização de ensino, estas, exclusivamente endereçadas à região sul do país. Os três Quadros a seguir procuram demonstrar as respectivas situações: 1) total de recursos por tipologia de subvenção e região atendida (Quadro 1); 2) total de subvenções ano a ano e região a região (Quadro 2); 3) consolidação de recursos e percentuais respectivos por tipo de subvenção (Quadro 3). 
QUADRO 1

Subvenção por tipologia e região 1931-1937 - Valores em contos de réis

\begin{tabular}{|c|c|c|c|c|c|}
\hline & \multicolumn{4}{|c|}{ TIPO DE SUBVENÇÃO } & \\
\hline REGIÃO & S1 & S2 & S3 & TOTAL & $\%$ \\
\hline SUL & $2.280: 000$ & $2.065: 500$ & $4.207: 300$ & $8.552: 800$ & 17,9 \\
\hline SUDESTE & $20.724: 825$ & $5.867: 750$ & - & $26.592: 575$ & 55,8 \\
\hline NORTE & $2.819: 000$ & $125: 000$ & - & $2.944: 000$ & 6,2 \\
\hline NORDESTE & $5.741: 000$ & 2.715:000 & - & 8.456:000 & 17,8 \\
\hline CENTR0-OESTE & $687: 500$ & 399:000 & - & 1.086:500 & 2,3 \\
\hline TOTAL & $32.252: 325$ & $11.172: 250$ & $4.207: 300$ & $47.631: 875$ & 100 \\
\hline
\end{tabular}

\section{QUADRO 2}

Total de subvenções ano a ano / região a região - valores em contos de réis

Período: dezembro 1931 - dezembro 1937

\begin{tabular}{|c|c|c|c|c|c|c|}
\hline Ano/Região & Sul & Sudeste & Norte & Nordeste & Centro-Oeste & Total \\
\hline 1931 & $500: 000$ & $235: 500$ & $200: 000$ & $59: 000$ & $17: 000$ & $1.011: 500$ \\
\hline 1932 & $758: 500$ & $1.476: 450$ & $166: 500$ & $330: 500$ & $9: 500$ & $2.741: 450$ \\
\hline 1933 & $1.458: 400$ & $2.441: 375$ & $299: 000$ & $675: 000$ & $40: 500$ & $4.914: 275$ \\
\hline 1934 & $1.510: 400$ & $4.578: 750$ & $475: 500$ & $1.614: 000$ & $83: 500$ & $8.262: 150$ \\
\hline 1935 & $1.215: 000$ & $4.062: 500$ & $610: 000$ & $1.305: 000$ & $243: 000$ & $7.435: 500$ \\
\hline 1936 & $1.651: 000$ & $6.194: 000$ & $598: 000$ & $2.201: 000$ & $328: 000$ & $10.972: 000$ \\
\hline 1937 & $1.459: 500$ & $7.604: 000$ & $595: 000$ & $2.271: 500$ & $365: 000$ & $12.295: 000$ \\
\hline Total & $8.552: 800$ & $26.592: 575$ & $2.944: 000$ & $8.456: 000$ & $1.086: 500$ & $47.631: 875$ \\
\hline
\end{tabular}

\section{QUADRO 3}

Consolidação de recursos por tipologia de subvenção - valores em contos de réis Período: dezembro 1931 - dezembro 1937

\begin{tabular}{|c|c|c|}
\hline Tipologia & Recursos & $\%$ \\
\hline Subvenção 1 & $32.252: 325$ & 67,7 \\
\hline Subvenção 2 & $11.172: 250$ & 23,5 \\
\hline Subvenção 3 & $4.207: 300$ & 8,8 \\
\hline Totais & $47.631: 875$ & 100 \\
\hline
\end{tabular}

Neste esquema demonstrativo, é importante lembrar que $\mathbf{S 1}$ sofreu uma diluição de verbas em vista dos recursos de baixa remuneração e do grande número de instituições de caridade que recorreram ao auxílio, muitas vezes, sendo atendidas com quantias que não chegavam a 500\$000 (quinhentos mil réis) ou não passavam de 1:000\$000 (um conto de réis). Assim, o que surpreende é menos o montante de recursos empenhados e mais a natureza e a quantidade de instituições, o que nos leva a especular 
tanto sobre a notável população à margem dos direitos efetivos de cidadania e fora dos direitos apostos na esfera do trabalho e seus desdobramentos legais (previdência, medicina, férias, aposentadoria etc.), quanto à relativa facilidade de as instituições caritativas angariarem recursos.

Em relação às regiões atendidas, o sudeste foi o maior beneficiário da política de subvenções. Ali se instalava a maioria das instituições, sobretudo, aquelas localizadas em Minas Gerais, com expressivo número de casas de Misericórdia, asilos para mendicantes e outros, e também porque, a antiga capital da República recebeu uma atenção especial do governo da época com significativa monta de recursos.

De fato, o volume de subvenções aplicado em instituições estabelecidas na cidade do Rio de Janeiro, superou em muitos milhares de contos de réis os recursos direcionados para uma ou mais regiões, como aconteceu em relação ao norte, ao nordeste e centro oeste se tomados em separado, ou ainda, se considerarmos em conjunto a região nordeste com uma ou outra das duas.

No levantamento efetuado, o Rio de Janeiro beneficiou-se de um montante de recursos em torno de 11.897:365\$0000, sendo 85\% para atender S1, e 15\% para atender S2. Esses valores representaram $25,04 \%$ do total de seis anos de subvenções. Vista como polo centralizador e disseminador da pauta política nacional, a cidade teria atuado como um dos foros de sustentação para a legitimidade do regime. Aprofundando essa distinção entre o sudeste e as demais regiões, desde a data em que foi concedida a primeira subvenção, em dezembro de 1931, até dezembro de 1937, foram canalizados recursos para S1, S2 e S3, estimados em 47.631:875\$000 (quarenta e sete mil, seiscentos e trinta e um contos, oitocentos e setenta e cinco mil réis), com o sudeste recebendo 26.592:575\$000, ou 55,8 \% do total de recursos.

Em determinadas ocasiões, um mesmo decreto de subvenção era reservado somente para atender instituições localizadas no Rio de Janeiro. Esse foi o caso dos Decretos 20993 de 25/1/1932, destinando 319:250\$000 para trinta e sete instituições, do Decreto 22.330, com 509:250\$000 para trinta e uma instituições, e, ainda, do Decreto 1331 de 30/12/1936, com auxílios de 926:000\$000 para o atendimento de quarenta e oito instituições.

Para este último e mais significativo montante, dentre alguns dos estabelecimentos atendidos vinculados à Igreja católica constavam: Dispensário Irmã Paula (10:000\$000); Abrigo Tereza de Jesus (3:000\$000); Asilo São Luiz da Velhice Desamparada (2:000\$000); Missão da Cruz (1:500\$000); Pequena Cruzada da Irmã Terezinha de Jesus (1:000\$000); Casa da Criança da Associação dos Anjos da Caridade da Lagoa (1:500\$000); Escola de Santo Adolfo das Filhas de Maria Imaculada (1:000\$000); Sodalício da Sacra Família (750\$000), etc. 
Outro desequilíbrio é percebido para a região sul do país. Ali, o principal foco das subvenções esteve calcado nos serviços de nacionalização do ensino. Tais recursos atingiram $49,2 \%$ do total da região ou $8,8 \%$ do montante subvencionado.

Embora se tenha dito acertadamente que a questão da nacionalização do ensino encontraria no Estado Novo o momento decisivo de sua resolução, foi com o surgimento da Caixa de Subvenções que começou a ser atingida por dentro a construção de uma idéia nacionalista através da educação. Isto antecipou em alguns anos as medidas adotadas em 1938. Nesse ano, entraram em vigência três dispositivos sobre a questão: o Decreto-Lei de 18 de abril, legislando sobre a proibição de organizações estrangeiras; o Decreto 639 de 20 de agosto, sobre cotas de imigração; e o Decreto-Lei 868 de 20 de novembro, sobre a nacionalização do ensino.

O sul do país somente adquiriu importância na geografia em virtude desse fracionamento favorável às políticas de nacionalização do ensino. A percepção que começou a amadurecer no Estado era de que uma educação distanciada da nacionalidade poderia gerar a criação de "várias nações" em confronto com a necessidade de abrasileiramento dos métodos pedagógicos. A política das subvenções para esse campo alheio à caridade foi de impacto considerável, entrando diretamente "em choque com a existência de núcleos imigratórios nas zonas de colonização, (...) que haviam implantado seus próprios sistemas de educação básica, em suas línguas de origem":21

O "abrasileiramento" destes núcleos de imigrantes era visto como um dos elementos cruciais do grande projeto cívico a ser cumprido através da educação, tarefa que acabou se exercendo de forma muito mais repressiva do que propriamente pedagógica, mas na qual o Ministério da Educação se empenharia a fundo. ${ }^{22}$

A julgar pelos recursos destinados para esta finalidade, parece que o "perigo estrangeiro" era mais latente em Santa Catarina. Do total de subvenções de tipo $\underline{\mathbf{S 3}}$, os catarinenses receberam em torno de 2.160:000\$000 ou o equivalente a 51,3\%. O Rio Grande do Sul, estado com forte presença de alemães e italianos, foi o que menos recebeu de auxílios para a nacionalização do ensino no período com apenas 17,1 \% das subvenções, ou 716:900\$000.

21 SCHWARTZMAN, Simon; BOMENY, Helena Maria Bousquet e COSTA, Vanda Maria Ribeiro. Tempos de Capanema. $2^{\text {a }}$.ed. São Paulo: Paz e Terra/FGV, 2000.

22 SCHWARTZMAN, Simon; BOMENY, Helena Maria Bousquet e COSTA, Vanda Maria Ribeiro. Tempos de Capanema, p.93. 


\section{Conclusão: Subvenções e catolicismo: menos justiça e mais caridade}

Com a existência da Caixa de Subvenções apareceu a força organizacional da Igreja. Tanto os institutos religiosos quanto as organizações laicas influenciadas ou geridas por católicos cumpriram várias e estratégicas funções para que as fontes de recursos nunca esgotassem. Beneficência e caridade, educação, missões de catequese, artes e ofícios eram os nichos de um mercado de dons no qual estava presente menos uma ação voltada para a justiça social ou para a repartição dos bens e da riqueza.

Será que o interesse das instituições católicas na política das subvenções alojaria a ideia de realização dos princípios da Doutrina Social da Igreja? A concretização da justiça social via subvenções, encontrava claros limites quando a prática da caridade, pela ação da mesma política, passou a se configurar não apenas na esmola ocasional do rico, na atitude do particular católico, ou no reforço do imaginário do "primeiro damismo". Essa política consistiu na criação objetiva de um sistema, no exercício de um domínio que pouco tinha a ver com a justiça. De forma que somente foi possível existir um projeto de tal amplitude porque a justiça social foi lesada, e a palavra caridade passou a designar certo número de obras características que se organizaram dentro de uma coerência e em função do abismo (e da sua manutenção) entre a riqueza e a pobreza.

A recepção da encíclica Quadragesimo anno de Pio XI (1931), com sua menção às regiões novas e aos problemas colocados pela tricotomia urbanização-pobreza-industrialização, teria despertado maior preocupação dos católicos brasileiros em termos de desenvolvimento de uma política sintonizada com os aspectos de assistência. Todavia, parece que a questão que moveu a Igreja católica teria sido articular um problema de natureza religiosa e um problema de natureza política. Novamente, a Igreja ocuparia a lacuna entre aqueles grupos incorporados pelas políticas trabalhistas e previdenciárias, e entre os grupos desprotegidos pela legislação e sujeitos a uma lembrança assistencialista, sabendo que esse lugar era propício não somente para o surgimento, mas para a expansão de suas instituições.

Herdeira do visceral antiliberalismo católico do século XIX, e, em grande medida, aliada do tradicionalismo oligárquico, a Igreja brasileira somente modificaria seu comportamento na década de 1920, aí preocupada fundamentalmente com a atmosfera de contestação da ordem social. Para Hans-Joachim König, a Igreja, que também na América Latina teve que enfrentar cada vez mais a concorrência de filosofias e ideologias seculares e que tinha perdido sua posição de monopólio ideológico devido à dissolução do contexto culturalreligioso uniforme, modificou seu comportamento e passou a interessar-se fortalecida também pela questão social. Algo que também é válido para o Brasil. ${ }^{23}$

23 KÖNIG, Hans-Joachim. A questão social na América Latina e no Brasil. Fins do século XIX, inícios do século XX. 
A relação entre a política de subvenções e o catolicismo pode ser reforçada e mais bem avaliada pelo importante papel cumprido pelas congregações religiosas. Administrando prelazias e missões de catequese indígena, colégios, casas de caridade, asilos, hospitais, ou prestando serviços de enfermagem nas conferências vicentinas e casas de misericórdia, congregações femininas e masculinas eram largamente atendidas pelos recursos da Caixa de Subvenções.

É sintomático que o primeiro decreto de subvenções tenha beneficiado diversos estabelecimentos das Missões Salesianas do estado do Amazonas com duzentos contos de réis: Associação Beneficente do Rio Madeira, Hospital São José de Porto Velho, Santa Casa de São Gabriel do Rio Negro, Instituto Dom Bosco, Escola Agrícola de São Gabriel do Rio Negro e Prefeitura Apostólica do Rio Negro. ${ }^{24}$

A presença dessas congregações foi constante nos decretos que canalizavam auxílios, além do que, muitas delas desdobravam suas funções entre ensino e assistência, ao mesmo tempo administrando colégios e gerindo casas de caridade, abrigos para crianças, moças e idosos. Dentre as congregações com esses múltiplos interesses, mais atuantes e mais beneficiadas pelas subvenções destacavam-se: Pequena Cruzada da Irmã Terezinha de Jesus/RJ, surgida em 1926 e gerida pelas irmãs dominicanas, Orfanato Dom Silvério de Cataguazes/MG, fundado em 1912 pelas irmãs carmelitas, Colégio Nossa Senhora de Lourdes de Palmares/PE, fundado em 1924 pelas irmãs da congregação franciscana de Nossa Senhora do Bom Conselho, que também mantinham a instituição em Porto Alegre, Oratório Festivo Beato D. Bosco, dos salesianos, com casas, pelo menos em Aracaju e Ponte Nova/MG, Colégio Imaculada Conceição de Fortaleza, fundado em 1867 pelos vicentinos, Colégio Santa Tereza de Jesus, do Crato/CE, fundado em 1923 pela congregação das Filhas de Santa Tereza de Jesus, Orfanato Nossa Senhora do Calvário, fundado em 1926 pela congregação das irmãs de Nossa Senhora do Calvário.

De igual forma, a presença de missões de catequese e de assistência no centro-oeste e norte do Brasil no programa de subvenções era avassaladora: Hospital da Prelazia do Rio Branco/AM, Missão da Ordem Terceira de São Francisco em São Luiz de Cáceres/MT, Prelazia de Guajará Mirim/ MT, Missão Dominicana de Conceição do Araguaia/MT, Missão Salesiana do Araguaia/MT, Missão Salesiana de Lageado/MT, Missão Salesiana entre os índios Chavantes/MT.

In: KÖNIG, Hans-Joachim; SCHÜLY, P. Gunther, S. J.; SCHNEIDER, P. José Odelso, S. J. (orgs.) Consciência social. A história de um processo através da Doutrina Social da Igreja. São Leopoldo: Unisinos, 1994, p.139.

24 Cf. Decreto 20.792 de 14 de dezembro de 1931. In: BRASIL. Colleção das Leis da República dos Estados Unidos do Brasil, v.IV, Atos do Governo Provisório (dezembro), p.119. 
Quando se comentou anteriormente em "mercado de dons", é necessário insistir num aspecto. O sociólogo Maurice Godelier analisa o dom como um "ato pessoal" e em qualquer sociedade considerada, hierarquizada ou não, ele está presente em todos os campos da vida social nos quais as relações pessoais continuam a desempenhar um papel dominante. Godelier sublinha que "O caráter pessoal do dom não desaparece necessariamente mesmo quando entre aquele que dá e aquele que recebe não existe nenhuma relação pessoal direta, nenhum conhecimento mútuo e mesmo quando há intervenção de intermediários". ${ }^{25}$

O programa de subvenções permitiu a criação de um mercado de dons que assumiu com nitidez a forma de circuitos filantrópicos ou de circuitos de uma caridade radicalmente monetarizada. Dentro da lógica do programa estava menos em causa a "redenção" dos desvalidos por meio da distribuição de justiça social, ou de uma talvez quimérica igualdade de direitos; e sim, o exercício de uma pálio-caridade que não se realizava sem a concomitante monetarização propiciada pelo poder público. Mas era uma prática que não somente deveria ser continuada, senão, aprofundada pelo trânsito de um componente essencial na relação: o dinheiro.

Esta argumentação significa que o "dinheiro" deve ser considerado um bem imprescindível para a construção de vínculos entre as mais diversas esferas sociais e, particularmente, no tocante ao tipo de política examinada aqui. O "dinheiro" foi um ente indispensável na configuração da afinidade eletiva entre Igreja e Estado. O "dinheiro" se constituiu como uma categoria não hostil ao componente moral que regia a atitude das instituições, porque houve a introdução de outras referências que se diferenciavam de uma relação pura e simplesmente mercantil, chamemos de justiça, caridade, benfeitoria, ou qualquer outra coisa.

A estruturação de uma proposta assistencial que tinha caráter público foi deslocada para uma abordagem privada, no âmbito da modelagem católica e fundamentada em concepções religiosas. Interpretando agora as palavras do padre Asterio Paschoal em chave conclusiva, tal reflexão deveria despertar no pobre certa consciência de sua condição, mas, provavelmente, sem colocar em questão as contradições históricas que resultaram nela e desinteressada em desenvolver uma perspectiva política sobre a mudança dela, uma vez que sua sobrevivência estava mais ou menos assegurada.

É possível, ainda, um último avanço na direção de avaliarmos o grau de caráter impessoal da política de subvenções. Com duas ilustrações pontuais tomadas de uma série de correspondências entre os responsáveis pelas instituições católicas e o governo Vargas, fica mais explícita o quão movediça era a prática de auxílios e o quanto ela se desdobrava em atitudes políticas

25 GODELIER, Maurice. O enigma do dom. Rio de Janeiro: Civilização Brasileira, 2001, p.25. 
ditadas pela racionalização, ou não. A despeito da frequencia pela qual as missões de catequese eram atendidas, algumas alegavam dificuldades de manutenção, quando consideradas suas várias funções.

Uma missão civilizatória junto aos índios não significava somente convertê-los e adaptá-los ao mundo cristão. Segundo monsenhor Pedro Massa, porta-voz das Missões Salesianas do Amazonas na correspondência a Vargas, eram inúmeras as vicissitudes surgidas caso não se atribuísse uma subvenção constante às missões na importância de duzentos contos de réis.

Como era sabido pelo presidente Getúlio, as missões eram consideradas obras de assistência pública, porque além do número de institutos assistenciais que mantinham, como asilos, escolas, oficinas, hospitais, postos de pronto-socorro e povoações indígenas elas também se destacavam:

Pela sua atuação nas fronteiras do Brasil com a Colômbia, Venezuela e a Bolívia, onde exercem uma louvável atividade nacionalista na defesa indireta das fronteiras, com o ensino da língua nacional, história pátria, alfabetização dos índios, sua fixação no solo, sua defesa sanitária e ensino agrícola e profissional, incorporando-os assim à vida civilizada no país. Dadas, porém, as circunstâncias expostas, a diminuição sensível de socorros particulares (Rockfeller Foundation, NYC), a falta de auxílios por parte do governo do Amazonas (...) tornam-se, com meu pesar, insuficientes as subvenções que nos são concedidas, pelo que ouso me dirigir à $\mathrm{V}$. Excia. - que tem tido para conosco repetidos gestos de proteção e amparo, que penhoram imenso minha gratidão - solicitando de sua benevolência queira conservar as subvenções votadas, majorando a da Prelazia de Porto Velho até a importância de 200:000\$000.

Rio de Janeiro, 9 de abril de 1935. Mons. Pedro Massa ${ }^{26}$

A queixa de monsenhor Pedro Massa foi relativamente compensada. A partir de junho de 1935, as Missões Salesianas da região amazônica e os seus serviços derivados foram atendidos, de acordo com os decretos localizados, em 1.125:000\$000 (mil e cento e vinte e cinco contos de réis). ${ }^{27}$

Já, a solicitação da irmã Vasconcellos, diretora do Dispensário dos Pobres do Sagrado Coração de Fortaleza foi ignorada abreviando-se seu pedido por uma negativa do MESP. Em novembro de 1937, às voltas com um déficit de 45:457\$410 (quarenta e cinco contos, quatrocentos e cinquenta e sete mil e quatrocentos e dez réis) a irmã "implorava" ao magnânimo coração de Vargas um auxílio particular para o pagamento das dívidas com

26 Gabinete Civil da Presidência da República. CODES 35. Lata 34. Ministério da Educação e Saúde Pública. Depto. de Saúde Pública. Ofício s/n. Ano de 1935. Ora, se o pedido de subvenções teria de passar, conforme a Lei, por uma série de procedimentos racionalizados, questiona-se a forma pela qual o religioso aborda a presidência da República através de uma comunicação direta, sem os trâmites burocráticos necessários e obrigatórios. A impessoalidade modernizadora reivindicada é destruída por essa relação afetiva.

27 Cf. os seguintes decretos: n.211 de 26/6/1935; n.214 de 1/7/1935; n.289 de 12/8/1935; n.393 de 28/10/1935; n.797 de 4/5/1936; n.828 de 19/5/1936; n.1549 de 5/4/1937. 
vistas a preparar um "belo natal para os pobres". Num lacônico despacho ao rodapé do ofício, o ministro Gustavo Capanema negava a subvenção, argumentando que a instituição já recebera o auxílio federal de 30 contos:

Dispensário dos Pobres do S. Coração.

Fortaleza.

Exmo. Snr. Dr. Getúlio Vargas.

Apesar de minha pequenez, eu tenho a ousadia de apresentar-me diante de V. Excia. para implorar vossa caridade.

Encarregada do Dispensário dos Pobres do Sagrado Coração, não obstante ter recebido 30:000\$000 de Subvenção Federal, isto não foi suficiente para extinguir o déficit de 45:457\$410 que me ficou do ano de 1936.

Venho por meio desta implorar do vosso magnânimo coração, um auxílio particular de 50:000\$000 com que possa pagar as dívidas que me restam e preparar um belo natal para os pobres.

Irmã Vasconcellos.

21 de novembro de 1937

Despacho: A instituição já recebeu o auxílio federal de 30 contos (Gustavo Capanema,

4 de dezembro de 1937). ${ }^{28}$

O processo formativo de uma doutrina republicana que iria regular as relações entre Estado e Igreja, se teve seu início logo em 1890, foi aprofundado no decorrer de quatro décadas, malgrado as disputas políticas desencadeadas por ambas as esferas. A plena estruturação do catolicismo num ambiente diferenciado do período imperial foi possível porque o Estado republicano soube prover e amparar sob o aspecto legal as organizações católicas. Em meados dos anos 1930, aos bens constitucionalmente conquistados pelos católicos, foram integradas com radicalidade as políticas de caridade pública sob o formato das subvenções. Isto conferiu à Igreja, enquanto corpo homogêneo, certa margem de liberdade quanto à acumulação e administração do seu patrimônio, mas também, acelerou o processo de organização eclesiástica.

Não seria exagero reafirmarmos a consolidação de uma "afinidade eletiva"29 que reluziu nas relações desse estado de coisas público/privado

28 Cf. Gabinete Civil da Presidência da República. CODES 35. Lata 121. Ministério da Educação e Saúde Pública. Depto. de Saúde Pública. Ofícios. Ano de 1937.

29 Inspirado no conceito de afinidade eletiva desenvolvido por Max Weber, Michael Löwy estudou as combinações entre duas correntes espirituais / intelectuais aparentemente, e para a opinião de senso comum situadas em campos totalmente opostos: o messianismo judaico e as utopias políticas libertárias. É bem possível que as relações entre o catolicismo e o governo Vargas comporte, para mais ou para menos os vários níveis ou graus de afinidade eletiva elencados por Löwy: 1) a afinidade pura e simples ou correspondência, no sentido de uma homologia estrutural que cria a possibilidade mas não a necessidade de uma convergência ativa; 2) a eleição, como atração recíproca; uma mútua escolha ativa das duas configurações socioculturais, conduzindo a certas formas de interação, estimulação recíproca e convergência; 3) a articulação, combinação ou "liga" entre parceiros, podendo resultar em diferentes modalidades de união; 4) a criação de uma figura nova a partir da fusão de elementos constitutivos. Cf. LÖWY, Michael. Redenção e utopia. O judaísmo libertário na Europa Central: um estudo de afinidade eletiva. São Paulo: Companhia das Letras, 1989, p.17. 
varguista e o catolicismo. Mais do que uma aliança temporária, essa afinidade garantiu estabilidade ao regime político, e propiciou notável crescimento das instituições católicas voltadas para o exercício da caridade, dada a significativa independência institucional de que a Igreja desfrutava. Ainda dentro desse quadro, é possível que as instituições católicas tenham seguido a prescrição de uma sociedade cuja filantropia deveria classificar e dissociar os "realmente necessitados" dos vadios que, porventura, se aproveitavam de uma situação induzida pela artimanha do "ócio".

O vasto emprego de fontes legislativas apresentadas como suporte das nossas hipóteses de trabalho, está longe de ser interpretado como uma história administrativa, ou encerrar a questão sobre a íntima conexão entre dois campos, religião e política. Espera evidenciar a interdependência histórica entre sistemas políticos e igrejas estabelecidas, abrindo possibilidades para que outros olhares possam inventariar a trama de construções jurídicas que tenham se constituído em medida de estabilidade daquela conexão. E, sobretudo, busquem problematizar os desafios, fragilidades e limites enfrentados pelos intermitentes processos de laicização da sociedade. 